$4^{\text {th }}$ International Meeting on Calcitonin Gene-Related Peptide (CGRP)

TheScientificWorld (2001) 1(S1), 29

ISSN 1532-2246; DOI 10.1100/tsw.2001.411

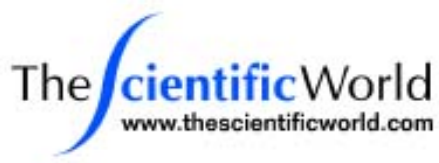

\title{
CGRP IN PRIMARY HEADACHES
}

\author{
Lars Edvinsson \\ Department of Internal Medicine, University Hospital, 22185 Lund, Sweden
}

Calcitonin-gene related peptide (CGRP)-containing nerve fibres supply vessels of different locations, both peripheral and cerebral. The intracranial vascular bed is supplied by CGRP fibers that originate in the trigeminal ganglion. When these fibres are activated they release CGRP as seen both in man and animals. CGRP initiates relaxant responses through an interaction with Gprotein coupled receptors that activate adenylyl cyclase. CGRP mediates relaxation via two functional receptors subtypes, the $\mathrm{CGRP}_{1}$ and the $\mathrm{CGRP}_{2}$ receptors. The former of the CGRP receptors has been characterized by the use of the antagonist $\mathrm{CGRP}_{8-37}$, compound 1 and BIBN4096BS as well as by molecular methods.

In migraine with or without aura, and in cluster headache there is a marked release of CGRP in parallel with the headache. Treatment of the patients with a triptan relieves the pain and the CGRP levels normalize, probably via a presynaptic effect. In cluster headache and in chronic paroxysmal hemicrania there is in addition release of VIP, from parasympathetic nerves. These clinical data strongly advocates the use of a CGRP blocker in the treatment of acute attacks of primary headaches. 

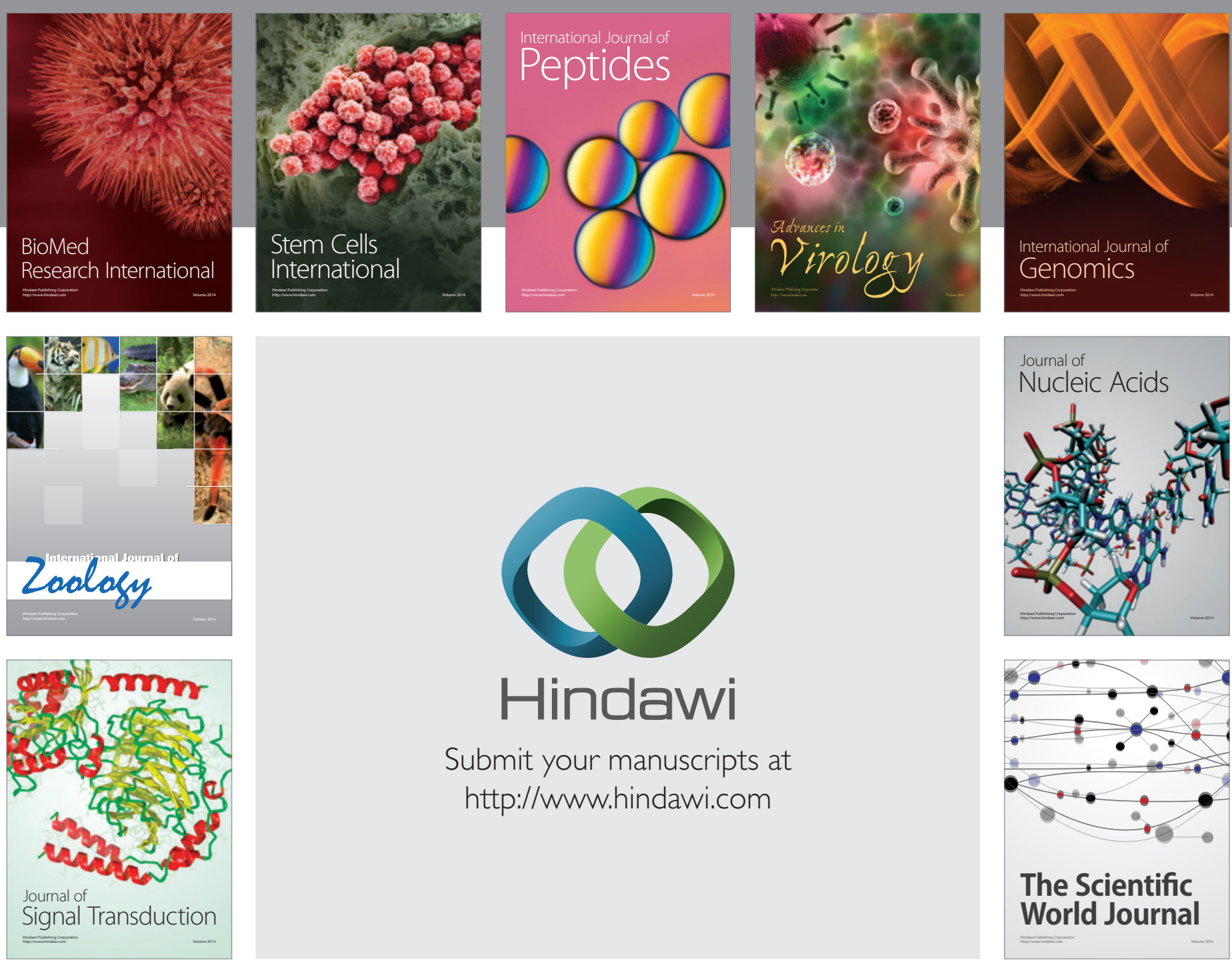

Submit your manuscripts at

http://www.hindawi.com
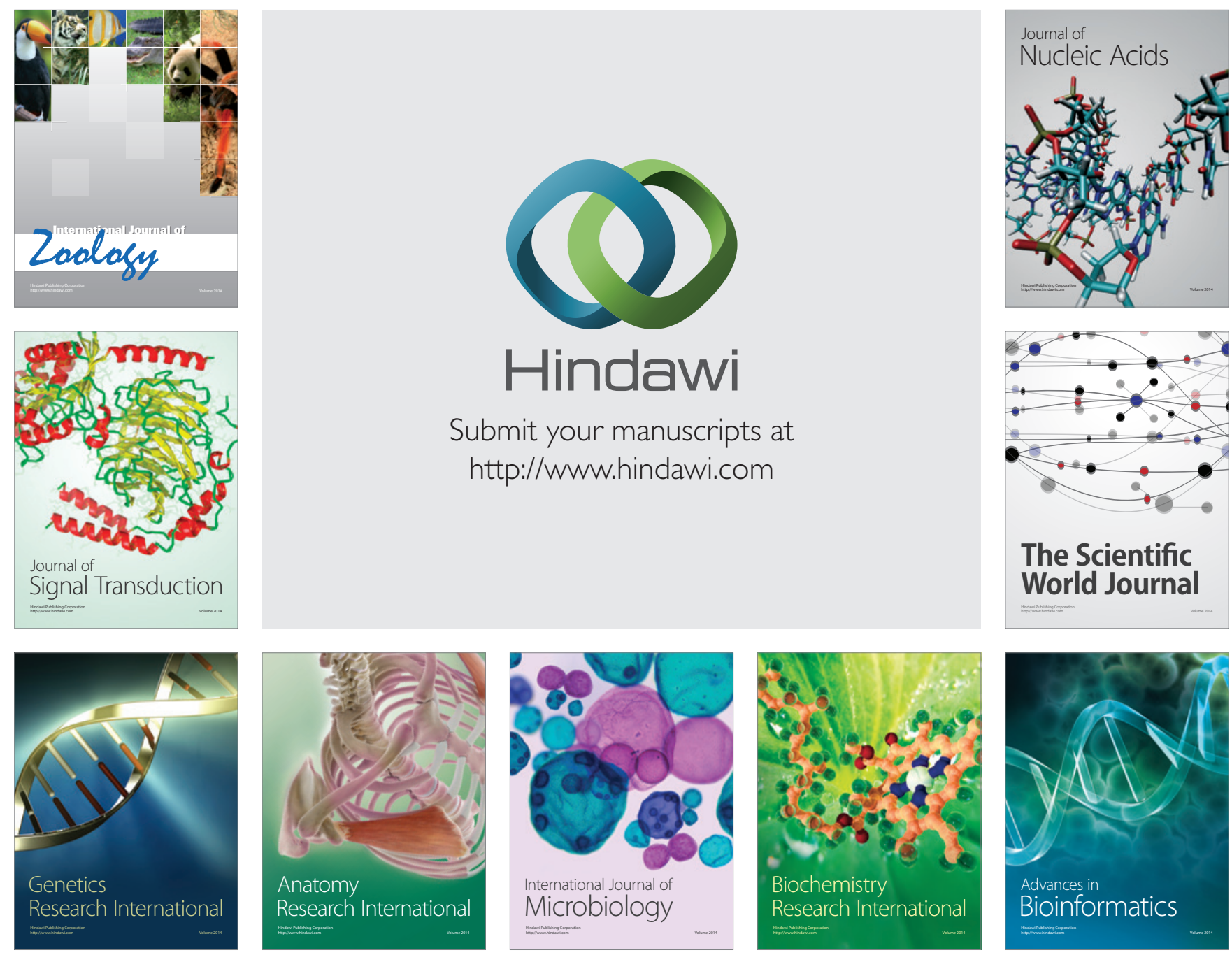

The Scientific World Journal
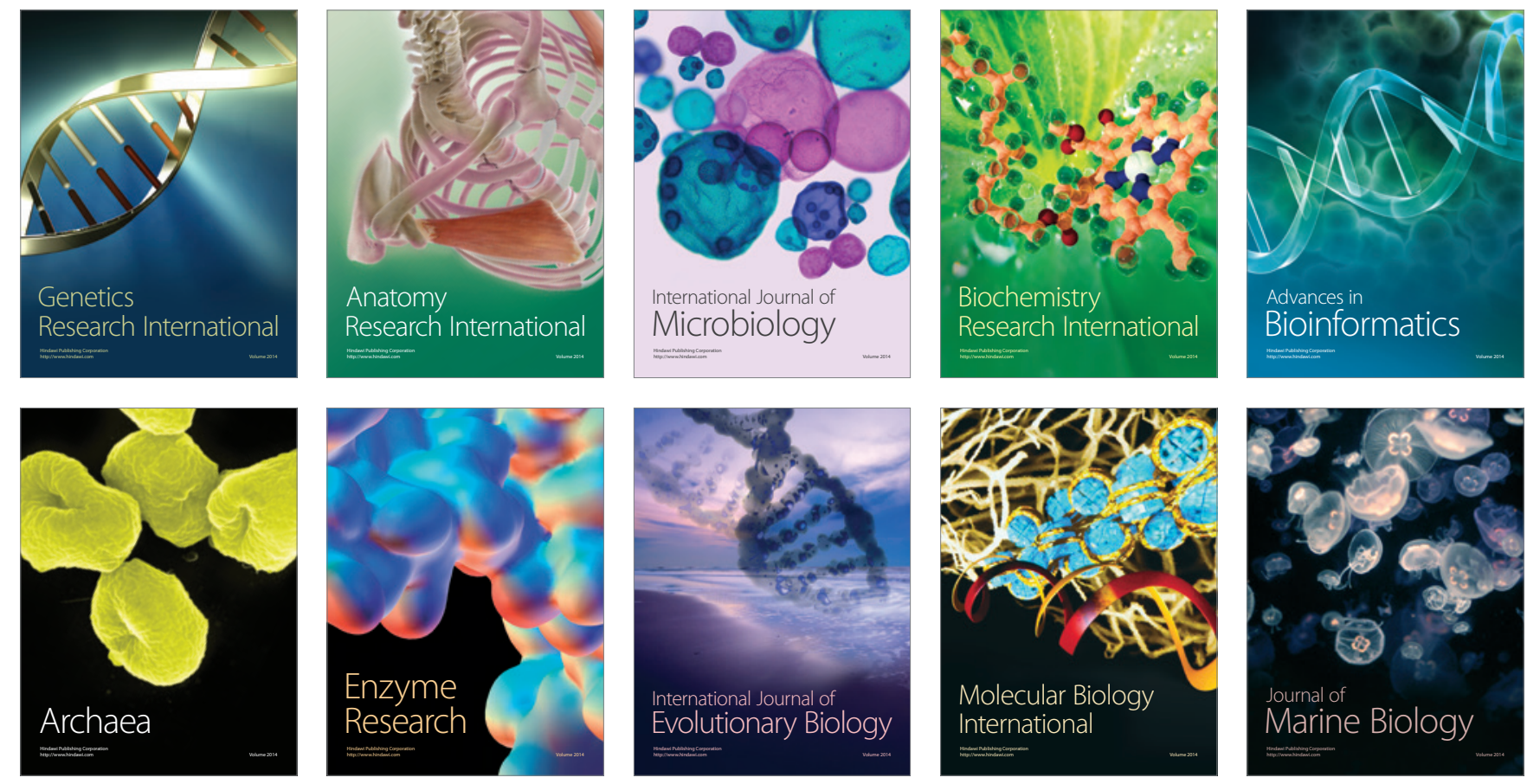